\title{
An Opportunity to Switch Energy Sources in Institutions in the Kilimanjaro Region, Tanzania and Benefit from Carbon Finance under the Sustainable Land Management Project
}

\author{
Stephen Mutimba ${ }^{*}$, Francis X. Mkanda ${ }^{2}$, Richard Kibulo ${ }^{1}$ \\ ${ }^{1}$ Camco Advisory Services (K) Ltd., Nairobi, Kenya \\ ${ }^{2}$ Sustainable Land Management Project, Kilimanjaro, Tanzania \\ Email: Stephen.Mutimba@camcocleanenergy.com, francis.mkanda@undp.org, rkibulo@yahoo.com
}

Received 22 October 2014; revised 28 November 2014; accepted 9 December 2014

Copyright (C) 2014 by authors and Scientific Research Publishing Inc.

This work is licensed under the Creative Commons Attribution International License (CC BY).

http://creativecommons.org/licenses/by/4.0/

c) (i) Open Access

\begin{abstract}
The sustainable land management (SLM) project is seeking to engage with public institutions to explore the possibility of using the energy-switch principle presented by the carbon market to reduce emissions from inefficient use of biomass energy and discharge of human waste into the environment. Such a switch will be a triple-win situation that improves the natural environment, reduces deforestation, and provides avenues for revenue generation. As such, it commissioned a study of the pattern of energy consumption in the institutions and the type of cooking stoves they employ. Results show that firewood (51\%) is the most widely used fuel because of availability, affordability, and reliability. The study also found that $56 \%$ of the institutions use energy-saving stoves, which is an opportunity that the project can seize to encourage use of alternatives sources of energy as opposed to biomass. In addition, $88 \%$ of the institutions expressed willingness to switch to biogas for cooking. This is yet another opportunity for scaling up the dissemination of renewable sources of energy in the region. Better adoption and wider use of renewable energy sources will take place when innovative financing mechanisms are devised to cover the high upfront cost of installing renewable energy systems. This has been one of the main barriers to scaling up the use of renewable in the region.
\end{abstract}

\section{Keywords}

Wood Fuel, Deforestation, Land Degradation, Carbon Finance, Renewable Energy, Cook Stoves

${ }^{*}$ Corresponding author.

How to cite this paper: Mutimba, S., Mkanda, F.X. and Kibulo, R. (2014) An Opportunity to Switch Energy Sources in Institutions in the Kilimanjaro Region, Tanzania and Benefit from Carbon Finance under the Sustainable Land Management Project. Open Journal of Soil Science, 4, 494-501. http://dx.doi.org/10.4236/ojss.2014.413047 


\section{Introduction}

This study seeks to provide an understanding of the pattern of energy consumption and cooking technologies employed by institutions in the Kilimanjaro Region because through a sustainable land management project entitled reducing land degradation on the highlands of the Kilimanjaro Region, the government of the United Republic of Tanzania (URT) is seeking to engage with public institutions to explore the possibility of using the energy-switch principle presented by the carbon market to reduce emissions from inefficient use of biomass energy and discharge of human waste into the environment. Such a switch will be a triple-win situation that improves the natural environment, reduces deforestation, and provides avenues for revenue generation. The energyswitch principle is in line with UNDP's Millennium Development Goal (MDG) Carbon Finance Facility, which is designed to contribute directly to achieving the MDGs as an innovative carbon-finance mechanism featuring emission offsets derived from a pool of projects. The facility represents a fundamental building block in UNDP's poverty, environment and MDG delivery strategy as it bridges developing countries with the carbon market. Over the last few years, the facility has removed barriers and established efficient host-country procedures, such as supporting project development via the facility. The first MDG carbon facility project is the Manna Energy Limited which in 2011 registered the World's First United Nations Clean Water Carbon Credit Program for enabling the deployment of community scale water treatment in the rural areas of Rwanda.

Like the rest of Tanzania, the Kilimanjaro Region is heavily dependent on biomass for its energy needs. Energy security in the region is affected by several key development factors, such as population growth $(1.8 \%$ annual average), accelerated urbanisation, economic development, and constant changes in prices of available energy sources [1]. Although the region's population growth rate is the twenty-fourth highest in the country, its density, at 124 people per square kilometre, is the eighth [2], implying that energy demand and consumption is concomitantly high. In fact, studies indicate that the consumption of wood-based biomass will increase in relative terms over the next 30 years as demographic growth continues to outstrip access to other modern fuels. The demand for cooking energy is projected to increase threefold [3] in urban Tanzania from 2002 to 2030, but the high price and low dependability of electricity will help maintain the demand for charcoal beyond that time.

In the region, increasing demand for wood-based biomass is visible in public institutions such as hospitals, prisons, boarding secondary schools, university campuses, and factories which consume large quantities of wood fuel, estimated at 35,661 tonnes of firewood and charcoal annually, thereby significantly contributing to deforestation and land degradation [4]. A recent study has shown that fuel wood is seldom the primary source of forest depletion. Other factors such as land clearing for agriculture and human settlement, commercial development and other land use changes are more important in causing forest depletion [5]. The fact that 35,661 tonnes of firewood and charcoal is consumed undoubtedly means that large patches of forests are being cleared per year. Besides, the Ministry of Natural Resources and Tourism estimates that $97.9 \%$ of total wood consumed in Tanzania is firewood and charcoal. To compound the problem, charcoal carbonization technologies that are presently being used for making charcoal are traditional and highly inefficient, with low conversion efficiency. The traditional methods include earth-mounds and pit kilns with conversion efficiencies ranging from $10 \%-14 \%$. This low efficiency often translates to raw material waste of up to $50 \%$. This means that the current tonnage of charcoal could, theoretically, be produced by half the weight of wood used. This situation has to be addressed if the remaining natural forest resources are to be conserved.

The introduction of energy-efficient technologies such as improved stoves, improved charcoal kilns as well as renewable energy technologies including solar photovoltaic (PV) systems, solar water heating, and briquetted charcoal date as far back as 1975 when biogas was introduced by SIDO (Small Industries Development Organization) according to the history of biogas in Tanzania [6]. Their adoption, however, has remained disappointingly low because of high transaction and distribution costs, and incomplete lack of regulation and enforcement. As an attempt towards addressing this problem, the SLM project funded by the URT Global Environment Facility (GEF), and UNDP intends to design an energy-improvement strategy for the Kilimanjaro Region. It is expected that the implementation of this strategy will lead to carbon emissions reduction linked to a carbon-credit-earning scheme and generate revenue from the sale of certified emission reduction (CER) credits under the carbon finance pilots. The first step in designing such a strategy was to examine types of energy and stoves preferred by institutions, and the latter's willingness to switch energy sources.

\section{Study Area}

Kilimanjaro is one of the 30 regions of the United Republic of Tanzania (Tanzania Mainland and Zanzibar Island). 
It is located in the north eastern part of Tanzania Mainland. It lies south of the equator between latitudes $2^{\circ}$ and $4^{\circ}$. Longitudinally, the region lies between longitudes $36^{\circ}$ and $38^{\circ}$ east of the Greenwich. To the north and east, it is bordered by Kenya, to the south, southwest, and west by the Tanga, Manyara, and Arusha Regions respectively. It covers an area of 13,209 $\mathrm{km}^{2}$ or $1.4 \%$ of the area of the entire Tanzania Mainland. The region comprises 7 administrative councils, namely Rombo, Hai, Moshi, Mwanga, Siha, Same and Moshi Municipality. In terms of institutions, major consumers of wood fuel, there are 1731 of according to the Kilimanjaro Regional Secretariat (2011) (Table 1).

\section{Methods}

A questionnaire was used to collect data because it is considered to be more appropriate than other techniques [7], for example the Rapid Rural Appraisal (PRA) and Participatory Rural Appraisal (RRA). Questionnaire design considered content, wording, and format, as recommended by another author [8]. To this end, a structured and open-ended questionnaire was formulated. The structured questions were used on issues where a specific range of known responses was expected. Such questions allow easier interpretation and analysis than openended questions. On the other hand, the open-ended questions were included so as to allow interviewees to construct their own accounts of experiences because the explanatory power of structured questions is limited. It comprised 22 variables that fell under five major sections that were considered as encompassing in as far as energy use and cooking devices are concerned. The sections included general information of the study area, institutional details, energy types used, reasons for those preferences, sources of biomass used, and carbon financing. Prior to the survey, a pilot study of 20 respondents was undertaken to check a number of questionnaire design aspects, such as clarity, appropriateness of the questions, and respondents' willingness to answer the questions.

A total of 300 institutions (17\%) were targeted (75 boarding schools, 9 colleges, 49 hospitals, 54 hotels, and 45 industries). However, the enumerators managed to interview only 204 (12\%) because of constraints such as time and distance to some of the institutions. These changes did not influence the final results as the difference between the target and achieved sample sizes is minor.

The judgment (purposive) sampling method was also employed [9], a non-probability sampling technique in which an experienced individual selects the sample based on his or her judgment about some appropriate characteristics required of the sample member. In this case, being an institution was the required characteristic. To ensure equal representation, we selected institutions to sample based on our knowledge of the establishments. Data analysis involved calculations of sums and percentages.

\section{Results and Discussion}

\subsection{Main Types of Energy Used by Institutions}

Firewood is the most widely used fuel in institutions followed by electricity, charcoal, liquefied petroleum gas (LPG) and others (Figure 1). Electricity is used mostly in industries, hotels and hospitals. Respondents revealed that they prefer firewood (Figure 2) to other sources not only because of availability, affordability and reliability, but also because the institutions have invested heavily in improved cook stoves (jiko banifu) that are designed for firewood use. That institutions have invested in energy-saving stoves is an indication that they are striving to contribute to the reduction in use of biomass energy.

Most of the institutions indicated that they would prefer to use LPG (37\%), followed by firewood (32\%) and biogas (12\%) respectively. The main reasons given for preferring LPG and biogas were that these fuels are convenient, efficient and clean, i.e., don't have some limiting factors like smoke during cooking. However, the major hindrance to the use of LPG is the high cost of cylinders and gas. For example the cost of an empty cylinder (38.0 kg) at Oryx Energies, one of suppliers of gas in Tanzania is TZS 110,000.00 or US $\$ 62.21$ (exchange rate as of 15 Aug 2014 was US $\$ 1.00$ to TZS 1661.49). Refilling such a cylinder costs TZS 120,000.00 or US $\$ 72.22$, i.e., approximately US $\$ 1.90 / \mathrm{kg}$. Compared firewood or charcoal, this price is about 950 or 11 times more expensive respectively. A 5-tonne truck of firewood retails at TZS $150,000.00$ or US $\$ 0.002 / \mathrm{per} \mathrm{kg}$, while a bag of charcoal (50 - $60 \mathrm{~kg}$ ) goes for TZS 18,000 or US $\$ 0.18 / \mathrm{kg}$. This high disparity in prices forces institutions to use wood fuel notwithstanding the limiting factors.

In the case of biogas, some educational institutions mentioned that school holidays posed a challenge in the 
Table 1. Institutions in the Kilimanjaro Region, Tanzania.

\begin{tabular}{|c|c|c|c|}
\hline \multirow{2}{*}{ Type of institution } & \multicolumn{2}{|c|}{ Type of ownership } & \multirow{2}{*}{ Total } \\
\hline & Public & Private & \\
\hline Primary schools & 887 & 46 & 933 \\
\hline Secondary schools & 215 & 98 & 313 \\
\hline Teachers' colleges & 3 & 4 & 7 \\
\hline Vocational training centres & 6 & 71 & 77 \\
\hline University colleges & 1 & 4 & 5 \\
\hline Hospitals & 6 & 13 & 19 \\
\hline Health centres & 22 & 14 & 36 \\
\hline Dispensaries & 152 & 189 & 341 \\
\hline Total & 1292 & 439 & 1731 \\
\hline
\end{tabular}

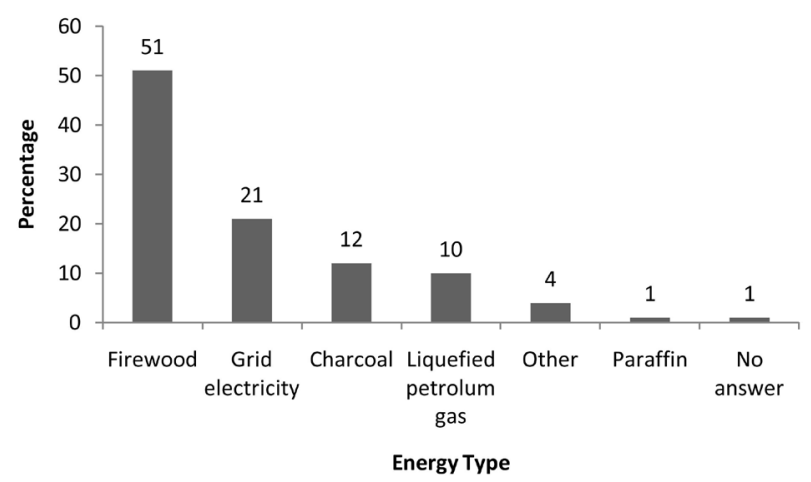

Figure 1. Main energy types used in institutions.

\section{Prefered Energy Source in Kilimanjaro}

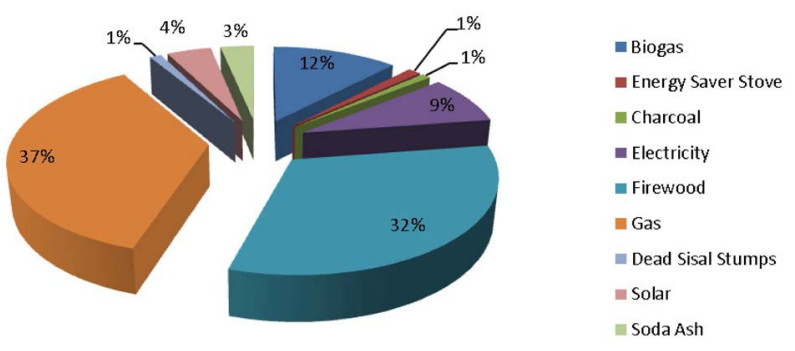

Figure 2. Preferred energy types by institutions.

feeding of bio-digesters. Once students are on holidays, there is a significant reduction in the amount of human waste to keep the biogas system operational.

A study by the WHO [10] states that the introduction of liquefied petroleum gas, despite initial investment costs, can result in a 7-fold return on investment. Government intervention is therefore required to lower the value added tax (VAT) of $16 \%$ imposed on LPG to make it more affordable than presently is the case. This recommendation applies to the whole range of renewable energy technologies to increase their affordability and adoption to spur growth of the industry in alternative energy sources.

\subsection{Sources of Wood Fuel}

Most institutions buy wood fuel from contracted suppliers who also organise delivery (Figure 3). In some instances, institutions also buy firewood from a number of local farmers in the neighborhood. However, public secondary schools in Moshi Municipal Council obtain firewood from suppliers through a centralised tendering system. 


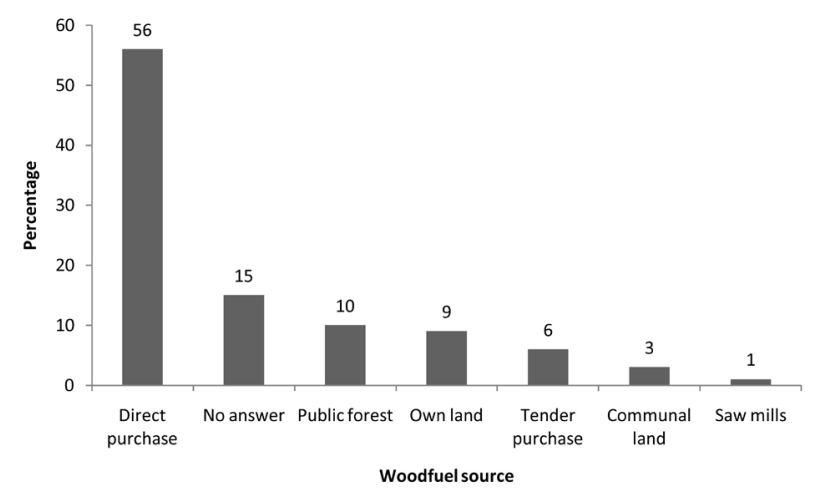

Figure 3. Sources of fuel wood for institutions.

Institutions like prisons, four of them in the region, and the police academy in Moshi Municipality obtain fire wood from government forests. The disadvantage is that their trucks have to cover increasingly long distances, up to $100 \mathrm{~km}$, to reach the forests. Such long trips lead to unsustainably high fuel costs. The problem is exacerbated during the rainy season when a round a trip can take up to three days, yet a load of firewood (5 tonnes) is consumed within 10 days only. Such a consumption rate means that a truck has to make at least three trips a month. Although high costs of fuel, frequency of firewood collection trips, and labour ultimately raises the price firewood, the institutions still view it as less costly to use biomass energy than alternative sources because apart from fuel expenses, the rest are considered as hidden. Institutions use their own trucks and labour (student and inmates in the case of the police academy and prisons respectively).

\subsection{Stoves Used in the Institutions}

A majority of the institutions (56\%) used energy saving stoves (jiko banifu) for cooking and heating purposes, particularly in secondary schools, colleges, and prisons (Figure 4 and Figure 5). A broad range of models in various shapes and capacities have been installed. Unfortunately, most of the stoves are badly designed, poorly operated, and maintained. Firewood is not cut into pieces that fit into the stove fire chamber. Instead, logs are used meaning that fire doors are left open during operation. It is, therefore, not surprising that most kitchens were found to be smoky, hot and unhygienic making the working environment very uncomfortable for the kitchen staff (Figure 4). In addition, the activities of cooks are not closely monitored and supervised by senior staff. Records of fuel consumption are not properly kept making it difficult to know how much fuel is consumed over a given period of time, and the cost. Worse still, firewood is not properly prepared, stored and dried before it is used (Figure 6).

Some of the institutions, however, still use the traditional 3-stone fire (13\%) and the charcoal stove (jiko $m k a a), 3 \%$. The use of the 3-stone fire, a traditional cooking system, is very inefficient. A high proportion of the fire wood burned goes to waste.

\subsection{Willingness to Switch Energy Sources}

Eighty eight percent of the institutions expressed willingness (Figure 7) to switch to biogas for cooking which can only mean that widespread adoption of this technology can take place once the issue of financing system installation costs, which is the main barrier, is addressed. The availability of funding under the SLM Project offers such an opportunity. This level of willingness is encouraging because if an energy-switch project were to initiated, it would be well received and implemented. A further opportunity for institutions to participate in the carbon credits is the abundance of suppliers of technologies for alternative energy sources not only within the region, but Tanzania as a whole. A good proportion of these are supplied by the Centre for Agricultural Mechanization and Rural Technology (CARMATEC) based in Arusha which has been operational for more than 20 years. CAMARTEC's mission is to develop and disseminate improve technologies suitable for agricultural and rural development. The organisation promotes improved household stoves, community stoves, biogas and solar energy systems. Camartec also works with other organisations to promote and disseminate knowledge of improved wood and charcoal cook stoves. 


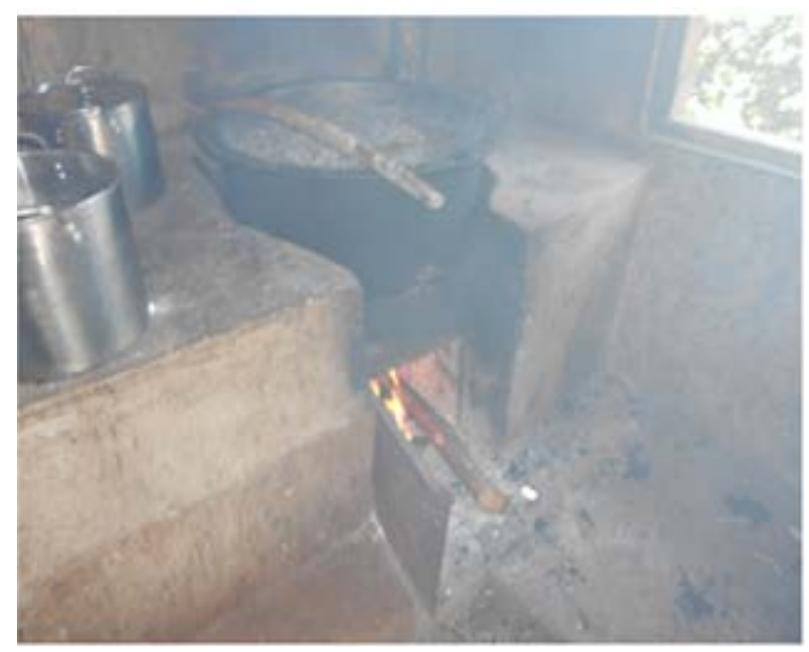

Figure 4. Poorly desined cook stoves.

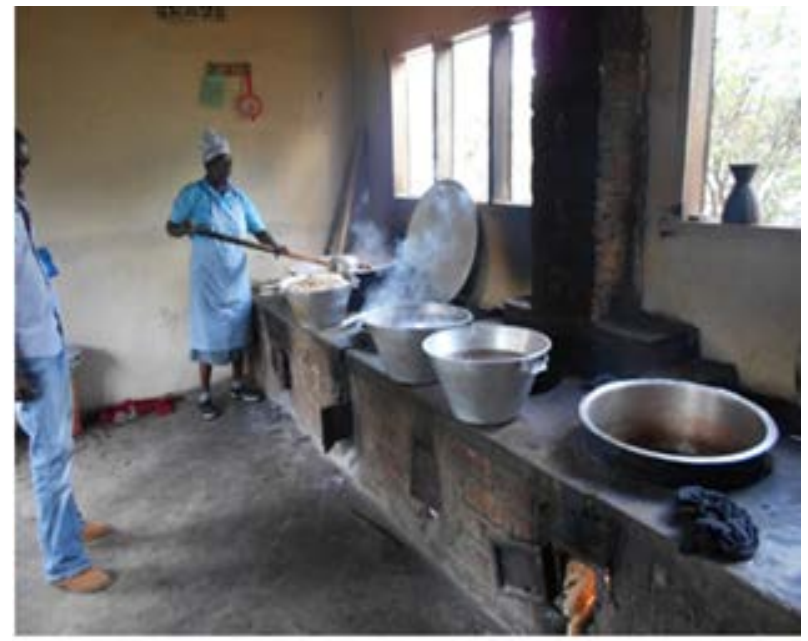

Figure 5. Cookstoves in a better organised kitchen.

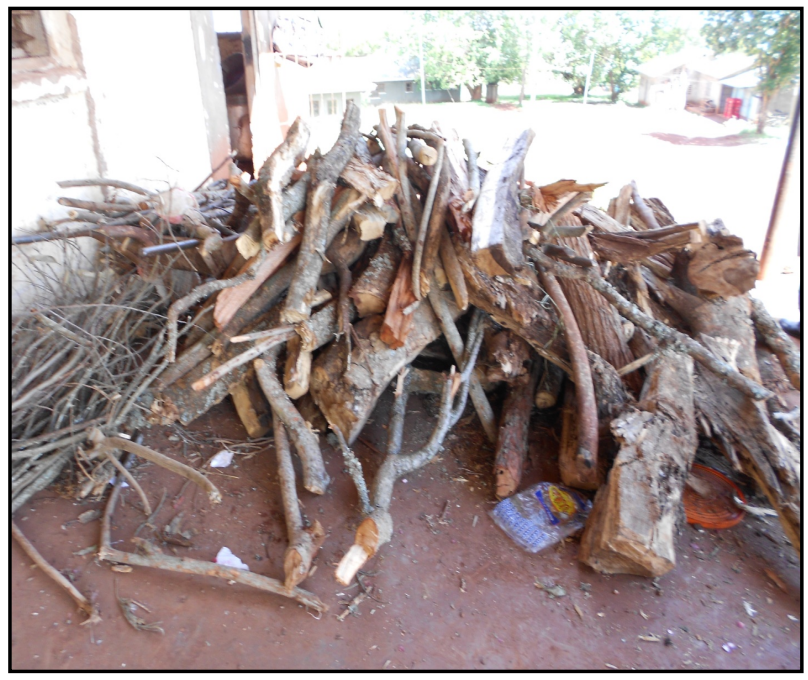

Figure 6. Firewood in a stored in a shed. 


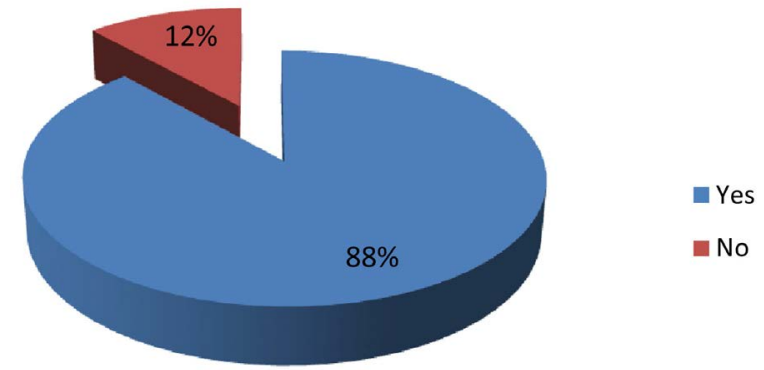

Figure 7. Willingness to participate in a carbon finance project.

Proliferation of different cook stove models is a good development in that it offers institutions various options based on capacity and price from the different suppliers. However, the stoves sector in Tanzania operates more or less in an environment that has no regulations or guidelines, making it difficult for local authorities to maintain order and discipline in the industry. Without regulations in place, manufacturers and vendors impose unreasonably high prices on the cook stoves, a factor that hinders wider adoption of this technology. For instance, a two burner gas cooker ranges from 2500.00 (US \$28.40) to KSH (Kenyan Shillings) 5000.00 (US \$56.72) in Kenya depending on the brand. In Tanzania, however, such types of stoves are about US \$61.00 and US \$77.00 a two and three-burner stove. Secondly, there are no standards specifying range and quality of materials that should be used, gauge, mode of construction and installation. Such standards would ensure that only those products meeting certain specifications qualify to be referred to as energy-saving stoves. Apart from models supplied by CARMATEC, TaTEDO (Tanzania Traditional Energy Development), SIDO, KIDT (Kilimanjaro Industrial Development Trust), and a few other reputable suppliers, most of the other models are not energy-saving. It can be safely deduced that these stoves are not having the intended impact of helping institutions reduce firewood consumption by $60 \%-70 \%$ which is achievable with well designed, properly operated and maintained improved institutional cook stoves.

\section{Conclusion}

This study sets out to provide an understanding of type of energy used, cooking devices, and willingness on the part of institutions to switch energy sources. As such, it reveals that firewood is by far the most widely used fuel because of availability, affordability, and reliability. That $88 \%$ of the institutions are willing to switch to biogas implies that there is an opportunity for energy-switch. This level of willingness means that widespread adoption of this technology can take place once the issue of financing system installation costs, which is the main barrier, is addressed. That $56 \%$ of the institutions have energy saving stoves for cooking is a sign of commitment towards reduction in the use of biomass energy. A further opportunity for institutions to participate in the use of the energy-switch principle is the abundance of suppliers of technologies for alternative energy sources not only within the region, but also within Tanzania as a whole.

\section{References}

[1] Kilimanjaro Regional Secretariat (2011) Kilimanjaro Region Strategic Plan 2011/12-2015/16.

[2] United Republic of Tanzania Population and Housing Census (2013) Population Distribution by Administrative Areas. National Bureau of Statistics, Ministry of Finance, Dar es Salaam, and Office of Chief Government Statistician, President's Office, Finance, Economy and Development Planning, Zanzibar, 244 p.

[3] Bauner, D., Sundell, M., Senyagawa, J. and Doyle, J. (2012) Sustainable Energy Markets in Tanzania; Report II: Analysis and Conclusions. Renewable Energy Technologies. Stockholm Institute, 36 p.

[4] Mutimba, S. (2014) Scaling up Fuel Efficient Technologies for Domestic, Institutions and Industrial Use with Carbon Benefits in the Kilimanjaro Region, Final Report. Consultancy Report, Sustainable Land Management Project. Regional Administrative Secretary-Kilimanjaro/United Nations Development Programme, Tanzania, 77 p.

[5] Arnold, J.E.M., Kohlin, G. and Persson, R. (2005) Fuelwoods, Livelihoods, and Policy Interventions: Changing Perspectives. World Development, 34, 596-611. http://dx.doi.org/10.1016/j.worlddev.2005.08.008

[6] Tanzania Domestic Biogas Programme (Undated) History of Biogas in Tanzania. http://www.biogas-tanzania.org/tdbp/about/category/history_of_biogas_in_tanzania 
[7] Parfitt, J. (1997) Questionnaire Design; Methods in Human Geography. A Guide for Students Doing a Research Project, 77-109.

[8] Valentine, G. (1997) Tell Me about Using Interviews as a Research Methodology; Methods in Human Geography. A Guide for Students Doing a Research Project, 110-253.

[9] Anon (Undated) Sampling Design and Procedures. http://www.cengage.com/marketing/book_content/1439080674_zikmund/book/ch16.pdf

[10] International Energy Agency and World Health Organization (2010) Energy Poverty: How to Make Modern Energy Access Universal? Special Early Excerpt of the World Energy Outlook 2010 for the 2010 UN MDG Review Summit. 
Scientific Research Publishing (SCIRP) is one of the largest Open Access journal publishers. It is currently publishing more than 200 open access, online, peer-reviewed journals covering a wide range of academic disciplines. SCIRP serves the worldwide academic communities and contributes to the progress and application of science with its publication.

Other selected journals from SCIRP are listed as below. Submit your manuscript to us via either submit@scirp.org or Online Submission Portal.
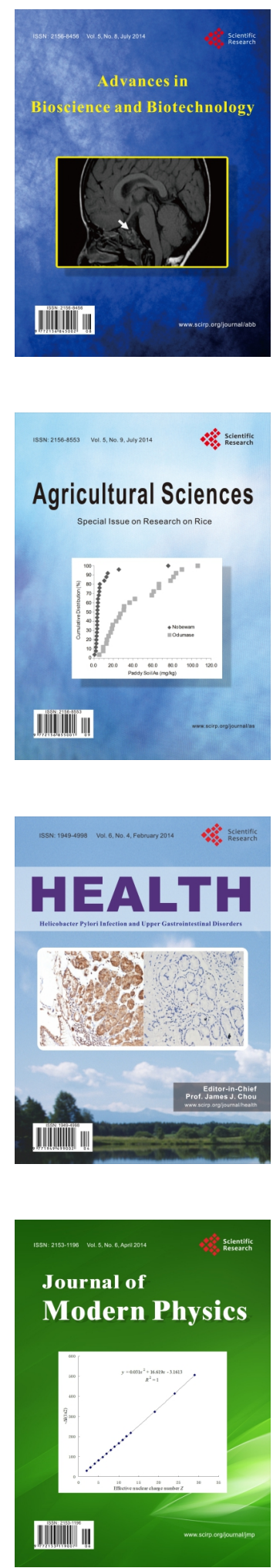
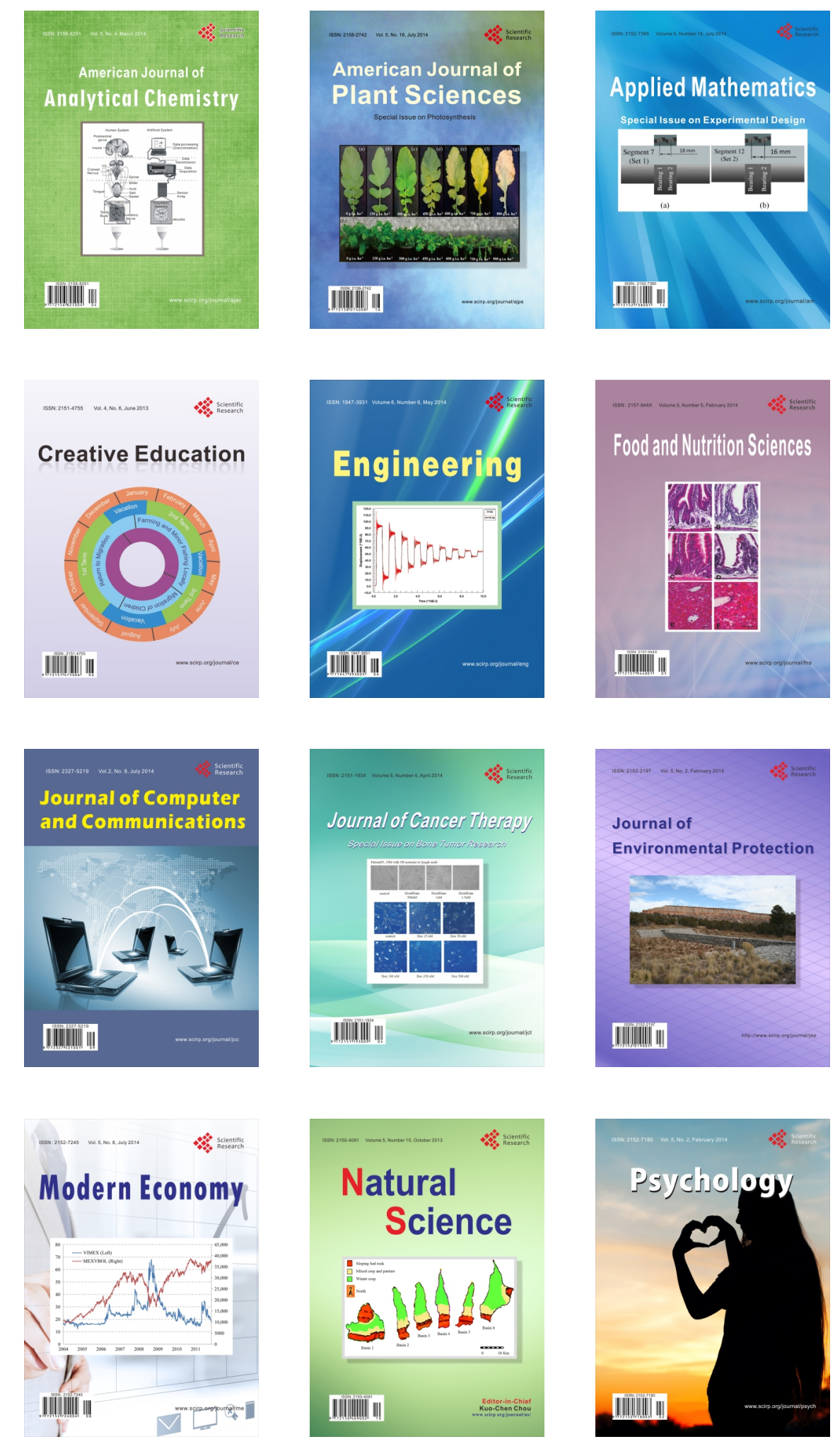